\title{
Provision of social-norms feedback to general practices whose antibiotic prescribing is increasing: a national randomized controlled trial
}

\author{
Natalie Gold ${ }^{1,2,3}$ D Michael Ratajczak ${ }^{1,4} \cdot$ Anna Sallis $^{1} \cdot$ Ayoub Saei $^{1} \cdot$ Robin Watson $^{1,5} \cdot$ Paul van Schaik $^{1,6}$. $^{1,7}$ \\ Sarah Bowen ${ }^{1,7} \cdot$ Tim Chadborn ${ }^{1}$
}

Received: 16 December 2020 / Accepted: 13 August 2021 / Published online: 27 December 2021

(C) The Author(s) 2021

\begin{abstract}
Aim The Chief Medical Officer of England writes an annual social-norms-feedback letter to the highest antibiotic-prescribing GP practices. We investigated whether sending a social-norms-feedback letter to practices whose prescribing was increasing would reduce prescribing.

Subject and methods We conducted a two-armed randomised controlled trial amongst practices whose STAR-PU-adjusted prescribing was in the 20th-95th percentiles and had increased by $>4 \%$ year-on-year in the 2 previous financial years. Intervention practices received a letter on 1st March 2018 stating 'The great majority (80\%) of practices in England reduced or stabilised their antibiotic prescribing rates in 2016/17. However, your practice is in the minority that have increased their prescribing by more than 4\%.'. Control practices received no letter. The primary outcome was the STAR-PU-adjusted rate of antibiotic prescribing in the months from March to September 2018.

Results We randomly assigned 930 practices; ten closed or merged pre-trial, leaving 920 practices — 448 in the intervention and 472 in the control. An autoregressive and moving average model of first order ARMA $(1,1)$ correlation structure showed no effect of the intervention $(\beta<-0.01, z=-0.50, p=0.565)$. Prescribing reduced over time in both arms $(\beta<-0.01, z=-36.36, p<$ $0.001)$.
\end{abstract}

Conclusions A social-norms-feedback letter to practices whose prescribing was increasing did not decrease prescribing compared to no letter.

Trial registration NCT03582072.

Keywords Antibiotics · Antimicrobial resistance $\cdot$ Feedback $\cdot$ Primary care $\cdot$ Social norms

Natalie Gold

n.gold@1se.ac.uk

1 Public Health England, Wellington House, 133-155 Waterloo Road, London SE1 8UG, UK

2 Centre for Philosophy of Natural and Social Sciences, London School of Economics, Houghton Street, London WC2A 2AE, UK

3 Behavioural Practice, Kantar Public, 4 Millbank, Westminster, London SW1P 3JA, UK

4 Department of Mathematics and Statistics, Lancaster University, Lancaster LA1 4YF, UK

5 Department of Anthropology, Durham University, Dawson Building, South Road, Durham DH1 3LE, UK

6 Centre for Applied Psychological Science, Teeside University, Middlesbrough, Tees Valley TS1 3BX, UK

7 School of Economics, Sir Clive Granger Building University Park, Nottingham NG7 2RD, UK

\section{Background}

The use of antibiotics is outpacing the discovery of new drugs, leading to antimicrobial resistance (AMR) as bacteria evolve to become 'superbugs', which are resistant to the drugs we use to treat them. In the UK alone in 2015, there were an estimated 52,971 cases of infection with antibiotic-resistant bacteria, resulting in 2172 deaths, which is similar to the burden of influenza, tuberculosis, and HIV combined (Cassini et al. 2019). A review of the problems posed by antimicrobial resistance commissioned by the UK Prime Minister in 2014 estimates a continued rise in resistance by 2050 , leading to the deaths of up to 10 million people worldwide each year (O'Neill 2016). Increased illness also has an economic cost, and the review estimates that the cost of AMR could be $\$ 100$ trillion worldwide by 2050 . 
A substantial driver of antibiotic resistance is the overprescription of antibiotics in primary care (Her Majesty's Government 2014). General practitioners (GPs) are often the first port-of-call for patients seeking medical help, and approximately $80 \%$ of antibiotics are prescribed in primary care, making this a suitable target for an intervention (Her Majesty's Government 2014). Statistical modelling suggests that between $8.8 \%$ and $23.1 \%$ of all antibiotic prescriptions could be classed as 'inappropriate', meaning that the antibiotic is likely to have zero or marginal benefit, which is likely to be outweighed by the potential risks of prescribing to the patient (Smieszek et al. 2018).

Researchers at Public Health England (PHE) conducted a comprehensive review and analysis of the behaviours that support antibiotic stewardship, and which of the drivers of these behaviours are amenable to change (Pinder et al. 2015). Based on this analysis, they conducted a national randomised controlled trial in 2014/15, testing a socialnorms-feedback letter, sent from England's Chief Medical Officer (CMO) to $791 \mathrm{GP}$ practices whose prescribing rate for antibiotics was in the top $20 \%$ in their local area (Hallsworth et al. 2016). The letter said that the practice was in the top $20 \%$ of prescribers in their area and listed three simple steps that prescribers could take to reduce inappropriate prescribing. The letter led to a $3.3 \%$ reduction in prescribing amongst GP practices that received it, with an estimated 73,406 fewer antibiotic items dispensed. Based on this evidence, similar letters were sent out to all practices whose prescribing was in the top 20\% nationally in 2015/16 and 2016/ 17 (the NHS Local Area Teams, which were used in the original letter, had been disbanded). An evaluation of the 2016/17 letter using a regression discontinuity design showed that the letter continued to have an effect, causing a $3.69 \%$ reduction in prescribing, with an estimated 124,952 fewer antibiotic items dispensed (Ratajczak et al. 2019). The intervention has also been successfully implemented in Ireland and Australia (Behavioural Economics Team of the Australian Government 2018; HSC Public Health Agency 2017).

However, evidence suggests that there is overprescribing in all practices, not just those in the top $20 \%$ of prescribers (Smieszek et al. 2018). Given the success of the socialnorms-feedback letter, we wanted to devise another socialnorms message that we could send to prescribers outside of the top 20\%. Practices are tasked with taking action to ensure that their prescribing behaviour is appropriate and to monitor judicious use of antimicrobials (NICE 2015). Antibiotic prescribing in primary care settings, measured in terms of antibiotic items being prescribed, has fallen by $16.7 \%$ from 2014 to 2018 (Public Health England 2018), which suggests that this message is having an effect and many practices are decreasing their prescribing. In the period of October 2016 to September 2017 (the most recent 12-month period of data available before the study's launch), only $20 \%$ of practices increased their prescribing frequency by more than $4 \%$, an increase that we judged to be greater than what might be expected due to natural variation alone.

At the time of our trial, there was no evidence on the effectiveness of providing GPs with social-norm feedback telling them that their practice is among a minority whose antibiotic prescribing is increasing. To address this knowledge gap, we conducted a randomized controlled trial in March 2018, of social-norms-feedback letters delivered to practices that were outside the top $20 \%$ of prescribers, but whose prescribing had increased by more than $4 \%$ between the financial year 2015/ 16 and financial year 2016/17. The intervention letter included a message telling GPs that they were in the minority of practices whose prescribing was increasing. We excluded the lowest prescribers from the trial (those whose prescribing was below the 95th percentile) because, after consulting with public health professionals, we decided it was unsuitable to send the lowest prescribers letters about overprescribing.

The aim of this trial was to determine whether a socialnorms-feedback letter reduces prescribing rates in GP practices prescribing between 20th and 95th percentiles whose prescribing had increased by more than $4 \%$ in 12 months before the intervention letter was sent, compared to a control group of the same characteristics who were not sent a letter.

\section{Methods}

\section{Trial design}

We conducted a two-armed randomised controlled trial. In February 2018, a letter and a 'Treating your infection' leaflet were sent to half of the practices between the 20th and 95th percentiles of practices whose antibiotic prescribing (adjusted for practice demographics) was increasing, informing them that they were in the minority of practices whose prescribing was increasing (see the Interventions section for more details, and Appendix 1 for examples of the letter and the leaflet). The control group did not receive a letter, which was standard practice.

\section{Participants}

There were 930 eligible GP practices in the trial. The prescribing indicator was the rate of dispensed antibiotic items per 1000 population for the practice, after applying the specific therapeutic group age-sex related prescribing units (STARPU) controls for age and sex. Practices were eligible if their prescribing fell between the 20th and 95th percentiles of prescribers for October 2016 to September 2017 (the most recent 12-month period of data available before the study's launch) and their antibiotic prescribing had increased by more than $4 \%$ in the financial year 2016/17 compared to the previous 
financial year, 2015/16. Practices above the 20th percentile were excluded because they were sent the standard practice social-norms letter, and practices between the 95th and 100th percentiles were excluded as outliers. The prescribing data are collected for each GP practice (individual prescribers' data is not available) on a monthly basis by the NHS Business Services Authority. Public Health England makes these data available on Fingertips. ${ }^{1}$ We used BNF code 5.1 and we divided the number of items prescribed by STAR-PU, in order to get the number of items dispensed per 1000 patients in the practice population when adjusted for age and sex.

\section{Interventions}

Letters from the CMO were sent to GPs at the end of February 2018, timed to land on March 1st, 2018, in an envelope that said on the outside that it was 'From the Chief Medical Officer, Professor Dame Sally C Davies', with a Department of Health and Social Care logo. The header stated that 'Antibiotic prescribing rates in your practice have increased.' Inside the text of the letter, there was a banner that informed GPs that 'The great majority (80\%) of practices in England reduced or stabilised their antibiotic prescribing rates in $2016 / 17$. However, your practice is in the minority that have increased their prescribing by more than $4 \%$.'

Like the letter sent to the top $20 \%$ in previous years, the letter listed three simple actions that the recipient could take to reduce unnecessary prescriptions of antibiotics: giving patients advice on self-care, offering a delayed prescription, and talking about the issue with other prescribers in the practice. All letters were accompanied by a copy of the patientfocused "Treating your infection" leaflet developed for the TARGET programme. A sample letter and the leaflet are reproduced in full in Appendix 1.

\section{Outcomes and sample size}

The primary outcome for the trial is the STAR-PU-adjusted rate of antibiotic prescribing in the 7 months following the intervention, March 2018 to September 2018. The trials were powered to detect a $2 \%$ change in antibiotic prescribing rate between arms of the trial, for each of March, April individually, and May to August combined (since prescribing is lower in those months), controlling for baseline prescribing behaviour - these were pre-registered outcomes, but by the time we analysed the trial, data was available for September 2018 as well, so we included that in our analyses; it does not affect the outcome. A $2 \%$ effect size was chosen as it was similar to the effects observed in comparable interventions carried out

\footnotetext{
${ }^{1}$ https://fingertips.phe.org.uk/profile/amr-local-indicators/data\#page/0/gid/ 1938132909/pat/46/par/E39000030/ati/19/are/E38000010
}

previously, and as smaller effect sizes would not represent a meaningful effect.

\section{Randomisation and masking}

A study investigator (MR) randomly assigned GP practices to intervention or control group, grouped by sampling a hypothetical binary distribution of control (0) and treatment (1) groups, where the probability of treatment group membership was 0.5. This was done using $\mathrm{R}$ (version 3.4.3) (Team 2017). GP names and addresses were matched to practices using GPs practice codes. ${ }^{2}$

Participants in intervention groups are likely to have been aware of the interventions they were assigned to, but may have been unaware that they were involved in a trial. However, information was published on the PrescQIPP AMS Hub, ${ }^{3}$ which supports Clinical Commissioning Group antimicrobial stewardship activity, including which GP practices had received letters, so we cannot be sure they were unaware. Since the prescribing dataset had to be matched with the dataset of GP names using GP practice codes, it was not practical to blind the study team to group assignment.

\section{Ethical approval}

Ethical approval was granted by the NHS Health Research Authority, REC reference: 14/LO/1544.

\section{Statistical analysis}

Monthly prescribing rates by different GP practices were considered to be independent, while those from the same GP practice are potentially correlated. Therefore, we used a statistical modelling approach that allows the monthly prescribing from the same GP practice to be correlated, by allowing the model residuals to be correlated. An autoregressive and moving average of first-order ARMA $(1,1)$ correlation structure was adopted here for the correlated residuals. The model included a trend in addition to the intervention. The data analysis was done in SAS using [SAS/STAT] software, Version 9.4 of the SAS 64 BIT WIN (SAS 2016).

\section{Results}

There were 930 practices randomly assigned in the trial. Feedback letters were sent to 451 (48.49\%) practices and $479(51.51 \%)$ were not sent a letter. The letter landed on

\footnotetext{
${ }^{2}$ https://digital.nhs.uk/services/organisation-data-service/data-downloads/gpand-gp-practice-related-data

${ }^{3}$ https://www.prescqipp.info/our-resources/webkits/antimicrobialstewardship/
} 
March 1st, 2018 and prescribing data from March to September 2018 inclusive was included in the analyses. By March 2018 there were 920 GP practices with prescribing data (data ceases when a practice merges or closes), leaving $448(48.17 \%)$ practices who received the intervention and $472(50.75 \%)$ in the control. See the trial flowchart in Fig. 1. A further 22 GP practices had their last month of prescribing between March and September 2018 and therefore had some missing data for the outcome measure. These practices were included in the analysis. The number of practices included in the analysis each month is shown in Table 1, along with the 7 months of prescribing data from March 2018 to September 2018 inclusive. The monthly mean for each arm is graphed in Fig. 2.

$>$ In the model, as expected, the monthly measurements (items per STAR-PU prescribed) from the same GP practice were highly correlated, with estimated autocorrelation $\rho=$ $0.970, \mathrm{SE}<0.01$ and moving average parameter $\gamma=0.77$, $\mathrm{SE}<0.01$ (for model coefficients see Table 2). The declining item rates trend in Fig. 2 was strongly supported by the results from the model, which showed a statistically significant negative trend in prescribing $(\beta<-0.01, z=-36.36$, $p<0.001$ ).

There was no evidence of an effect of the intervention: the correlated adjusted estimate of the intervention effect was negative but it was not statistically significant $(\beta<-0.01, z$ $=-0.50, p=0.565$ ) - see Table 2. Model diagnostics (not reported here) did not indicate any serious model failure.

\section{Harms and unintended effects}

The CMO's address was included in the letter, and she received correspondence about the letter, but no harms or unintended effects were reported.

\section{Discussion}

The social-norms-feedback letter to practices outside of the top $20 \%$ whose prescribing was increasing did not have a statistically significant effect $(\beta<-0.01, p=0.565)$. Prescribing was decreasing in both trial arms over the outcome period from March 2018 to September 2018 ( $\beta<$ $-0.01, p<0.001)$. The lack of effect of the intervention was surprising, given the evidence of effectiveness of previous social-norms-feedback letters to GPs in the UK (Hallsworth et al. 2016; Ratajczak et al. 2019) and internationally (Behavioural Economics Team of the Australian Government 2018; HSC Public Health Agency 2017).

There are various possible explanations why this letter was not effective.

Previous letters, which have been effective, targeted the highest $20 \%$ of prescribers (Behavioural Economics Team of the Australian Government 2018; HSC Public Health Agency 2017; Ratajczak et al. 2019), whereas these letters targeted practices whose prescribing was between the 20th and 95 th percentiles. There may be more scope for reducing inappropriate prescribing amongst higher prescribers.
Table 1 Antibiotic prescribing rates per STAR-PU for the overall sample, intervention, and control groups from March until September 2018 inclusive

\begin{tabular}{|c|c|c|c|c|c|c|}
\hline \multirow[t]{2}{*}{ Month } & \multicolumn{2}{|c|}{ Control } & \multicolumn{2}{|c|}{$\begin{array}{l}\text { Feedback } \\
\text { Intervention }\end{array}$} & \multicolumn{2}{|c|}{ Overall } \\
\hline & $\begin{array}{l}\text { Mean } \\
(\mathrm{SD})\end{array}$ & $N$ & $\begin{array}{l}\text { Mean } \\
(\mathrm{SD})\end{array}$ & $N$ & $\begin{array}{l}\text { Mean } \\
(\mathrm{SD})\end{array}$ & $N$ \\
\hline March & $\begin{array}{l}0.08 \\
(0.02)\end{array}$ & 472 & $\begin{array}{l}0.08 \\
(0.02)\end{array}$ & 448 & $\begin{array}{l}0.08 \\
(0.02)\end{array}$ & 920 \\
\hline April & $\begin{array}{l}0.06 \\
(0.01)\end{array}$ & 469 & $\begin{array}{l}0.07 \\
(0.02)\end{array}$ & 446 & $\begin{array}{l}0.07 \\
(0.02)\end{array}$ & 915 \\
\hline May & $\begin{array}{l}0.06 \\
(0.01)\end{array}$ & 468 & $\begin{array}{l}0.07 \\
(0.02)\end{array}$ & 444 & $\begin{array}{l}0.06 \\
(0.01)\end{array}$ & 912 \\
\hline June & $\begin{array}{l}0.06 \\
(0.02)\end{array}$ & 468 & $\begin{array}{l}0.06 \\
(0.01)\end{array}$ & 444 & $\begin{array}{l}0.06 \\
(0.01)\end{array}$ & 912 \\
\hline July & $\begin{array}{l}0.06 \\
(0.02)\end{array}$ & 465 & $\begin{array}{l}0.06 \\
(0.01)\end{array}$ & 443 & $\begin{array}{l}0.06 \\
(0.02)\end{array}$ & 908 \\
\hline August & $\begin{array}{l}0.06 \\
(0.02)\end{array}$ & 461 & $\begin{array}{l}0.06 \\
(0.01)\end{array}$ & 441 & $\begin{array}{l}0.06 \\
(0.02)\end{array}$ & 902 \\
\hline September & $\begin{array}{l}0.06 \\
(0.01)\end{array}$ & 461 & $\begin{array}{l}0.06 \\
(0.01)\end{array}$ & 439 & $\begin{array}{l}0.06 \\
(0.01)\end{array}$ & 900 \\
\hline Average over the outcome period & $\begin{array}{l}0.06 \\
(0.01)\end{array}$ & 3264 & $\begin{array}{l}0.06 \\
(0.02)\end{array}$ & 3105 & $\begin{array}{l}0.06 \\
(0.02)\end{array}$ & 6369 \\
\hline
\end{tabular}


Fig. 1 Trial profile

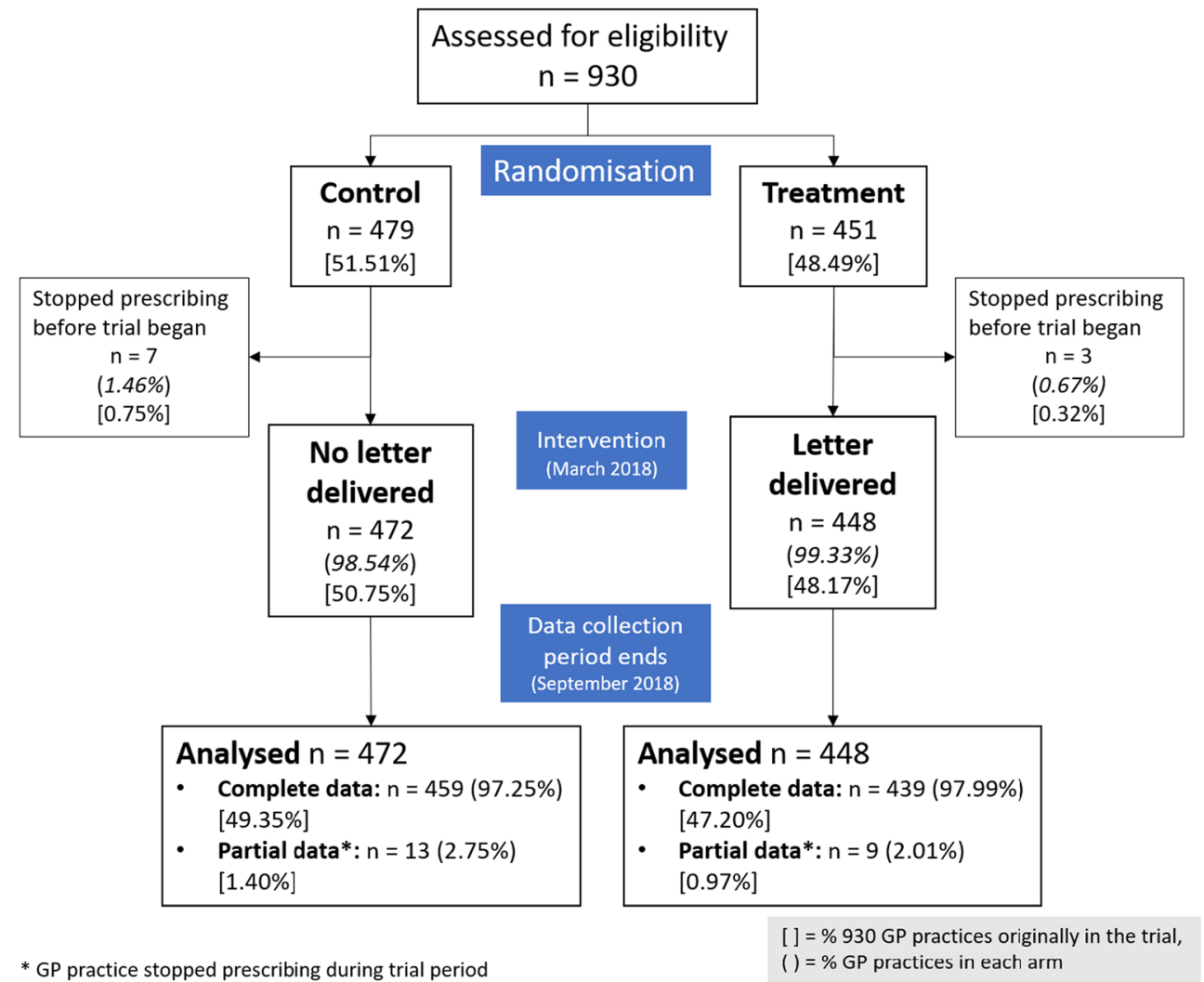

However, statistical modelling shows that all practices have scope for decreasing inappropriate prescribing (Smieszek et al. 2018). Nevertheless, the GPs who received the letters in this trial may have known that they were not in the highest prescribing practices and therefore not have been very concerned about their antibiotic prescribing rates. In a discussion at a workshop about giving prescribing feedback to primary care, participants said that GPs care about being outliers on prescribing indicators (i.e. very high or very low) and are more comfortable being in the middle (Steels et al. 2021).

Because the target group was different, the message was different from previous letters: instead of telling practices that they were in a minority of practices whose overall prescribing was high, we told them that they were in a minority of
Fig. 2 Monthly trend of prescribing mean over 8 months

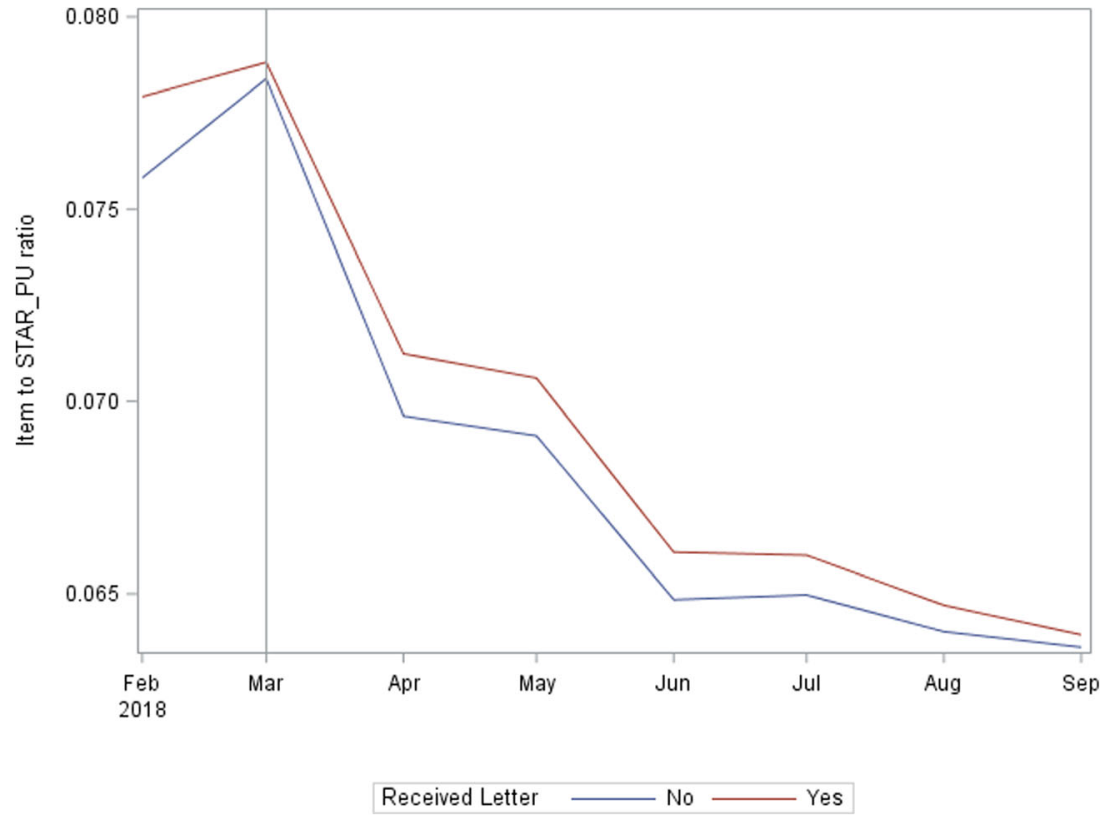


Table 2 Parameter estimates (Est) and their associated standard error (SE), z-value and $p$ value

\begin{tabular}{lllll}
\hline Parameter & Est & SE & $Z$-value & $P$ value \\
\hline Intercept & 0.07 & $<0.01$ & 117.52 & $<0.001$ \\
Received-letter & $<-0.01$ & $<0.01$ & -0.50 & 0.565 \\
Trend & $<-0.01$ & $<0.01$ & -36.36 & $<0.001$ \\
\hline
\end{tabular}

practices whose prescribing was increasing. The active ingredient of the message was intended to be the social norms part, about being in a minority: social norms have been effective in a variety of areas (Sheeran et al. 2016), including tax evasion (Hallsworth et al. 2017), energy usage (Ayres et al. 2013), and charitable giving (Agerström et al. 2016), and there is nothing in theory to suggest that the exact content of the message or what group they were the minority of would have an effect (Bicchieri 2016; Cialdini 2007). Possibly the social-norms message was less salient than in our previous letters, since although the red font in the body of the letter told GPs that their practice was in a minority, the large font header at the top of the letter said 'Antibiotic prescribing rates in your practice have increased'. In previous years, the letter header reinforced the social-norms message, saying 'Your practice is amongst the 20\% highest prescribers of antibiotics' (Hallsworth et al. 2016; Ratajczak et al. 2019). Antibiotic prescribing rates in your practice have increased, but most other practices reduced or stabilised their prescribing' or 'Compared to other practices, your prescribing rates have increased'.

We found that prescribing was decreasing over the trial period, with a negative trend across both arms. Possibly the letter has ceased to be effective as prescribing has come down. However, evidence shows that there is still plenty of scope for practices to reduce prescribing (Smieszek et al. 2018). There were many other national interventions happening at the same time, such as the Quality Premium, Commissioning for Quality and Innovation (CQUINs) quality improvement goals, national guidelines launched by the National Institute for Health and Care Excellence (NICE), and the extension of the TARGET (Treat Antibiotics Responsibly, Guidance, Education, Tools) toolkit resources via a number of workshops (Public Health England 2018). Many of these interventions were also happening in previous years, when the letter to the highest prescribers was shown to be effective (Hallsworth et al. 2016; Ratajczak et al. 2019). However, our letter listed three actions that GPs could take to reduce inappropriate prescribing and, if these actions were already widely known and implemented, maybe as a result of other campaigns, then the letter would simply have reinforced actions to reduce prescribing that were already happening.

As well as running the trial, we sent the standard letter to the highest $20 \%$ of prescribers, which landed on the same date as the intervention letter. An evaluation of its effectiveness, for instance using a regression discontinuity design, could help discriminate between some of the explanations for the lack of effectiveness of the letter in the present study. For instance, if the top $20 \%$ letter was effective, then that is consistent with the explanations that the message that prescribing was 'increasing' caused the lack of effect or that targeting prescribers outside of the top $20 \%$ is less effective. However, it is inconsistent with the explanation that the national campaigns have already led GPs to implement all the actions listed in our letters, as the same actions were included in the standard letter to the highest $20 \%$ of prescribers. Alternatively, if the top $20 \%$ letter was not effective, then that would support the explanations that reductions in prescribing have left less room for improvement, or that the actions listed are already widely implemented, and it would not support explanations that refer to differences in message content.

The other hypothesised active ingredient of these letters is the messenger - the CMO at the time Dame Professor Sally Davies. The fact that the present letter was not effective suggests it cannot solely be the messenger effect which has made previous letters effective.

Although social-norms interventions have been widely found to be effective (Sheeran et al. 2016), this is not the first socialnorms study to have returned a null result. Social-norms messages have failed to work in other healthcare interventions, including immunization (Leight and Safran 2019) and alcohol misuse (Foxcroft et al. 2015; Moreira et al. 2009), and there have been other null results in areas where they have previously been used successfully, such as energy usage (Harries et al. 2013). But it is hard to know why some interventions have been unsuccessful. Social-norms interventions are heterogeneous, and it may be that some types of social-norm interventions are not effective. Simply adding a photograph to a social-norms message aimed at increasing organ donation registration proved to be worse than an identical message with no image or an identical message with a logo, and less effective than the control arm using no persuasive message at all (Sallis et al. 2018). Message content and mode of delivery may be important (Dempsey et al. 2018). In this study, the mode of delivery and a very similar message have both been successful in the past (Behavioural Economics Team of the Australian Government 2018; Hallsworth et al. 2016; HSC Public Health Agency 2017; Ratajczak et al. 2019). Future research might investigate the effectiveness of different types of content of social-norms messages.

\section{Conclusion}

A social-norms-feedback letter to practices whose prescribing was increasing did not decrease prescribing compared to control practices who did not receive a letter. Prescribing decreased in both trial arms over the outcome period. There are 
various possible explanations why this letter was not effective in this instance. Further research could investigate them.

List of abbreviations $A M R$, Antimicrobial resistance; $B N F$, British National Formulary; $C M O$, Chief Medical Officer; $G P$, General practitioner; $P H E$, Public Health England; $R C T$, Randomized controlled trial; $S T A R-P U$, Specific therapeutic group age-sex related prescribing units

Supplementary Information The online version contains supplementary material available at https://doi.org/10.1007/s10389-021-01645-4. Acknowledgments We would like to thank Professor Dame Sally Davies GCB DBE FRS FMedSci, UK Special Envoy on AMR.

Author contributions NG jointly formulated the trial hypothesis, contributed to the development of the trial materials, managed the implementation and analysis of the trial, contributed to the interpretation of the results, and wrote the first draft of the paper.

MR jointly formulated the trial hypothesis, developed the trial materials, downloaded the data on which the trial implementation was based, conducted the power analysis, conducted the randomization, and implemented the trial.

ASallis jointly formulated the trial hypothesis, oversaw the development of the trial materials, and contributed to the interpretation of the results.

ASaei oversaw the data analysis and provided the final model.

RW downloaded the data for the results analysis and did preliminary data analysis.

PvS did preliminary data analysis.

SB created the trial profile and did preliminary data analysis.

TC jointly formulated the trial hypothesis and was the Senior Responsible Officer for the project.

All authors read and approved the final manuscript.

Funding Public Health England; As part of its standard responsibilities, employees of the funder of the study had a role in the study design, data interpretation, and writing of the report. The corresponding author had full access to all the data in the study and had final responsibility for the decision to submit to publication.

Availability of data and materials The datasets generated and analysed during the current study are available on Fingertips, https://fingertips.phe. org.uk/profile/amr-local-indicators/data\#page/0/gid/1938132909/pat/46/ par/E39000030/ati/19/are/E38000010

Declarations Ethical approval was granted by the NHS Health Research Authority, REC reference: 14/LO/1544.

Competing interests The authors declare that they have no competing interests.

Ethical approval and consent to participate Ethical approval was given by the Health Research Authority, London - Harrow Research Ethics Committee, REC Reference 14/LO/1544; this included a waiver on GPs or GP practices having to consent to participate since that would have undermined the trial results, particularly from the control group, and these effects would be disproportionate to the intervention.

Consent for publication Not applicable.

Open Access This article is licensed under a Creative Commons Attribution 4.0 International License, which permits use, sharing, adaptation, distribution and reproduction in any medium or format, as long as you give appropriate credit to the original author(s) and the source, provide a link to the Creative Commons licence, and indicate if changes were made. The images or other third party material in this article are included in the article's Creative Commons licence, unless indicated otherwise in a credit line to the material. If material is not included in the article's Creative Commons licence and your intended use is not permitted by statutory regulation or exceeds the permitted use, you will need to obtain permission directly from the copyright holder. To view a copy of this licence, visit http://creativecommons.org/licenses/by/4.0/.

\section{References}

Agerström J, Carlsson R, Nicklasson L, Guntell L (2016) Using descriptive social norms to increase charitable giving: the power of local norms. J Econ Psychol 52:147-153. https://doi.org/10.1016/j.joep. 2015.12.007

Ayres I, Raseman S, Shih A (2013) Evidence from two large field experiments that peer comparison feedback can reduce residential energy usage. J Law Econ Org 29(5):992-1022. https://doi.org/10.1093/ jleo/ews020

Behavioural Economics Team of the Australian Government (2018) Nudge vs superbugs: a behavioural economics trial to reduce the overprescribing of antibiotics. Australian Government, Australia

Bicchieri C (2016) Norms in the wild: how to diagnose, measure, and change social norms. Oxford University Press, Oxford

Cassini A, Högberg LD, Plachouras D, Quattrocchi A, Hoxha A, Simonsen GS et al (2019) Attributable deaths and disabilityadjusted life-years caused by infections with antibiotic-resistant bacteria in the EU and the European Economic Area in 2015: a population-level modelling analysis. Lancet 19(1):56-66. https:// doi.org/10.1016/S1473-3099(18)30605-4

Cialdini RB (2007) Descriptive social norms as underappreciated sources of social control. Psychometrika 72(2):263. https://doi.org/10.1007/ s11336-006-1560-6

Dempsey RC, McAlaney J, Bewick BM (2018) A critical appraisal of the Social Norms Approach as an interventional strategy for healthrelated behaviour and attitude change. Front Psychol 9:2180. https://doi.org/10.3389/fpsyg.2018.02180

Foxcroft DR, Moreira MT, Almeida Santimano NML, Smith LA (2015) Social norms information for alcohol misuse in university and college students. Cochrane Database Syst Rev 12:CD006748. https:// doi.org/10.1002/14651858.CD006748.pub4

Hallsworth M, Chadborn T, Sallis A, Sanders M, Berry D, Greaves F et al (2016) Provision of social norm feedback to high prescribers of antibiotics in general practice: a pragmatic national randomised controlled trial. Lancet 387(10029):1743-1752. https://doi.org/10. 1016/s0140-6736(16)00215-4

Hallsworth M, List JA, Metcalfe RD, Vlaev I (2017) The behavioralist as tax collector: using natural field experiments to enhance tax compliance. J Public Econ 148:14-31. https://doi.org/10.1016/j.jpubeco. 2017.02.003

Harries T, Rettie R, Studley M, Burchell K, Chambers S (2013) Is social norms marketing effective? A case study in domestic electricity consumption. Eur J Mark 47(9):1458-1475. https://doi.org/10. 1108/EJM-10-2011-0568

Her Majesty's Government (2014) UK five-year antimicrobial resistance (AMR) strategy 2013-2018: annual progress report and implementation plan. Retrieved from https://www.gov.uk/government/ uploads/system/uploads/attachment data/file/385733/UK AMR annual_report.pdf

HSC Public Health Agency (2017) Surveillance of antimicrobial use and resistance in Northern Ireland, Annual Report, 2017. Retrieved from 
http://www.publichealth.hscni.net/sites/default/files/AMR_annual_ report_final_0.pdf

Leight J, Safran E (2019) Increasing immunization compliance among schools and day care centers: evidence from a randomized controlled trial. J Behav Public Adm 2(2):1-15. https://doi.org/10. 30636/jbpa.22.55

Moreira MT, Smith LA, Foxcroft D (2009) Social norms interventions to reduce alcohol misuse in university or college students. Cochrane Database Syst Rev 3:CD006748. https://doi.org/10.1002/14651858. CD006748.pub2

NICE (2015) Antimicrobial stewardship: systems and processes for effective antimicrobial medicine use. In: NICE guideline [NG15]. National Institute for Health and Care Excellence, London

O'Neill J (2016) Review on antimicrobial resistance tackling drugresistant infections globally. Retrieved from https://amr-review. org/sites/default/files/160518_Final\%20paper_with\%20cover.pdf. Accessed 22 Dec 2021

Pinder R, Berry D, Sallis A, Chadborn T (2015) Behaviour change and antibiotic prescribing in healthcare settings Literature review and behavioural analysis. Public Health England, London https://doi. org/10.25561/22194

Public Health England (2018) English Surveillance Programme for Antimicrobial Utilisation and Resistance (ESPAUR). Retrieved from https://assets.publishing.service.gov.uk/government/uploads/ system/uploads/attachment_data/file/759975/ESPAUR_2018_ report.pdf

Ratajczak M, Gold N, Hailstone S, Chadborn T (2019) The effectiveness of repeating a social norm feedback intervention to high prescribers of antibiotics in general practice: a national regression discontinuity design. J Antimicrob Chemother 74(12):3603-3610. https://doi.org/ 10.1093/jac/dkz392

Sallis A, Harper H, Sanders M (2018) Effect of persuasive messages on National Health Service Organ Donor Registrations: a pragmatic quasi-randomised controlled trial with one million UK road taxpayers. J Trials 19(1):513. https://doi.org/10.1186/s13063-018$2855-5$

SAS (2016) SAS/STAT, Version 9.4. SAS Institute Inc, Cary, IN

Sheeran P, Maki A, Montanaro E, Avishai-Yitshak A, Bryan A, Klein WMP, Miles E, Rothman AJ (2016) The impact of changing attitudes, norms, and self-efficacy on health-related intentions and behavior: a meta-analysis. Health Psychol 35(11):1178. https://doi. org/10.1037/hea0000387

Smieszek T, Pouwels KB, Dolk FCK, Smith DR, Hopkins S, Sharland M et al (2018) Potential for reducing inappropriate antibiotic prescribing in English primary care. J Antimicrob Chemother 73(suppl_2): ii36-ii43. https://doi.org/10.1093/jac/dkx500

Steels S, Gold N, Palin V, Chadborn T, van Staa TP (2021) Improving our understanding and practice of antibiotic prescribing: a study on the use of social norms feedback letters in primary care. Int $\mathbf{J}$ Environ Res Public Health 18(5):2602. https://doi.org/10.3390/ ijerph18052602

Team RC (2017) R: a language and environment for statistical computing. version 3.4.3. RC Team, Vienna

Publisher's note Springer Nature remains neutral with regard to jurisdictional claims in published maps and institutional affiliations. 